\title{
ATTITUDES AND PRACTICES OF SMOKING AMONG MALE STUDENTS OF ADVANCED LEVEL BIOLOGY STREAM TUITION CLASSES IN AN URBAN DISTRICT IN SRI LANKA
}

\author{
Umesha Perera $^{1 *}$, Shenal Perera ${ }^{1}$, Madara Perera ${ }^{1} \&$ Surangi Jayakody ${ }^{2}$ \\ ${ }^{1}$ Faculty of Medicine, University of Colombo, Sri Lanka \\ ${ }^{2}$ Department of Community Medicine, Faculty of Medical Sciences, University of Sri Jayewardenepura, Sri \\ Lanka
}

\begin{abstract}
Smoking has become a major public health problem worldwide, including Sri Lanka. In most of the cases initiation of smoking is seen in adolescence. A descriptive cross sectional study was conducted among male students of two selected Advanced Level Biology tuition classes in Gampaha to describe the attitudes and practices of smoking and associated factors. Two hundred male students were selected by a systematic sampling method. A self-administered questionnaire on socio-demographic data, questions to assess attitudes and practices of smoking and associated factors, was given. Chi square test was used to assess the significance and $p$ value of $<0.05$ was taken as significant. The overall prevalence of ever smoking was $16 \%$. Among them $27.3 \%$ had smoked more than 100 cigarettes (5 packs) up to now. Seven percent were daily smokers. Majority had tried their first cigarette at the age between 14-16 years $(54.5 \%)$. Current smoking habit observed among boys was positively associated with having a close friend who is a smoker $(\mathrm{p}=0.001)$, father $(\mathrm{p}=0.013)$ and brothers $(\mathrm{p}=0.001)$ who are smoking and favorable home environment for smoking $(\mathrm{p}=0.001)$. There was no significant association between academic performance and smoking behavior $(\mathrm{p}=0.061)$. Anti-smoking advertisements were negatively associated with current smoking $(\mathrm{p}=0.960)$. About one third of ever smokers $(30.3 \%)$ had a positive impact by seen pictorial health warnings on cigarette packets.
\end{abstract}

Keywords: Smoking, Adolescents, Attitudes, Practices

\section{Introduction}

Smoking has become a major public health problem worldwide, including Sri Lanka. It is currently responsible for the deaths of around 6 million people across the world each year with many of these deaths occurring prematurely (World Health Organization,1997).

Cigarette smoking is responsible for $90 \%$ of lung cancers, $40 \%$ of other cancers, $50 \%$ of cardiovascular diseases, $75 \%$ of respiratory diseases, $12 \%$ of all mortalities and $30 \%$ of deaths occurring between the age of 30 and 50 (Bartecchi et al, 1994).

Cigarette smoking is a behavior that is initiated primarily during the adolescent years. (Leventhal, 1980). Smoking initiation, particularly the primary transition from nonsmoker to experimental smoker remains poorly understood (Sherman et al, 1979). Smoking prevention programs would benefit from comprehensive, theory base studies of adolescent smoking initiation (Evans et al, 1979).

It has been determined that genomic damage by chemical and carcinogenic substances included in cigarettes is more severe in adolescents because their body's cell are immature and in the process of growing (Pavanello and Clonfero, 2000). Adolescents who start smoking at a young age, risk experiencing DNA damage and does the risk of lung cancer in their adulthood is increased (Wiencke and Kelsey, 2002). In addition, smoking has negative effects on all aspects of adolescents' lives given its relationship to juvenile delinquency including alcohol and drug use and violence (Camenga et al., 2006). Moreover and early first smoking experience increases the possibility of continuing to smoke as an adult (Khuder et al., 1999). Programmes for adolescents to prevent and stop smoking should be a priority in national adolescent health policy. 
Estimated annual mortality from tobacco-related illness is about 20,000 deaths that is approximately 57 people die per day due to tobacco use. Cigarette is the only product, which kills one out of two consumers. NonCommunicable Diseases (NCDs) have become the leading cause of morbidity in Sri Lanka and tobacco use is a recognized causal factor in the genesis of NCDs. The government of Sri Lanka had taken several initiatives to reduce smoking. Sri Lanka signed and ratified the framework convention on tobacco control (FCTC) in 2003. This was followed by the government taking initiatives to set up the National Authority on Tobacco and Alcohol (NATA) through an act of Parliament in 2006. Health warning have been printed on cigarette packs and advertising of cigarettes and tobacco products are highly restricted. Later, laws were imposed prohibiting smoking in public places (Ministry of Health, 2009).

The prevalence of ever smoking among adult males in Colombo district was 54.1\% (95\% CI 51.0-57.2), whereas prevalence of current smokers was 36.5\% (95\% CI 33.8\%-39.3\%). Among the ever smokers, prevalence of smoking was higher among the age group of 50-59 years of age (20.3\%), educated level GCE O/L or less (17.9\%), married (43.5\%), doing a job (44.4\%) and earns less than Rs. 40000.00 per month (38.6\%) (Chulasiri, 2014).

\section{Justification}

Once an adolescent begins to smoke, that behavior and the newly acquired states of a smoker may influence his or her perception and attitude on smoking. Earlier studies do not provide a clear understanding of smoking initiation among adolescents. Rather addressing the cessation of smoking it is more practical to seek the factors associated with initiation of smoking.

The factors associated with initiating (Kandel et al, 2004) and quitting (Sieminska et al, 2008) smoking have been investigated in high income countries. Peer pressure and delinquent behavior are amongst the reasons mentioned for the development of this habit while future health concerns, occurrence of illness, financial stress and better quality of life, pictorial health warning on cigarette packs were the main motivations for smoking cessation. Research evidence on this regard is lacking in Sri Lankan setting. Hence, a descriptive study was designed to describe the attitudes and practices of smoking and associated factors among male students in advanced Level biology stream tuition classes in Gampaha district, Sri Lanka.

\section{Methods}

Study design: A descriptive cross sectional study was conducted.

Study setting: The study was conducted in two selected advanced level biology tuition classes in Gampaha, Sri Lanka.

Study population: The male students of the advanced level biology tuition class following local syllabus in a government or a private school currently studying in Grade 12 and 13 were taken as the study population. Students of age over 19 years and who are residing in other districts were excluded.

Sample size and sampling: 200 students were selected from two tuition classes. In each tuition class 100 students were selected, 50 from grade 12 and 50 from grade 13.Systematic sampling method was used to select the eligible students.

Data collection: Self-administered questionnaire was used for data collection. Purpose of the study was explained prior to the visit and the permission was taken from the class authorities. Informed written consent 
was taken from the participants. Confidentiality of the data was assured. Filled questionnaires were checked then and there by the investigators for completeness.

Data analysis: Data was analyzed using the Statistical Package for Social Sciences (SPSS 21) software. Quantitative data were described using frequency distribution. Qualitative data were presented using percentages. Associations were assessed using chi square test.

Ethical consideration: Ethical clearance was obtained from the ethics review committee of the Faculty of Medicine, University of Colombo.

\section{Results}

\section{Description of the study sample}

Majority (92\%) of male students in the sample were Buddhists. Majority (38\%) had their monthly family income of 25000-49999 rupees followed by 36\% whose monthly family income were more than 50000 rupees. Majority (60.5\%) of the students received more than 1000 rupees per month for their own expenses and only $8 \%$ received less than 500 rupees for their own expenses per month.

\section{Prevalence of smoking}

Sixteen percent $(16 \%)$ of male students in the sample had smoked at least once in their life.

\section{Practices of smoking among students who had ever smoked}

Pattern of smoking, places of smoking and the way of getting cigarettes were considered as practices of smoking. Number of cigarettes smoked so far, age at first exposure, last time smoked and age at smoking an entire cigarette first time were considered under the pattern of smoking among students who had ever smoked (Table 1).

Table 1: Frequency distribution of pattern of smoking among male students who had ever smoked in the study sample

\begin{tabular}{lcc}
\hline Pattern of smoking & frequency & percentage $(\%)$ \\
\hline Number of cigarettes & 8 & 24.2 \\
Only one & 9 & 27.3 \\
$<5$ & 7 & 21.2 \\
$6-100$ & 9 & 27.3 \\
$>100$ & & \\
& 1 & \\
Age (years) at first exposure & 18 & 3.0 \\
$<14$ & 14 & 54.5 \\
$14-16$ & & 42.4 \\
$>16$ & 14 & \\
& 9 & 42.2 \\
Last time smoked & 10 & 27.3 \\
Last month & & 30.3 \\
Within last 2-12 months & 15 & \\
12 months ago & 8 & 3.0 \\
& & 27.3 \\
Age at smoking an entire cigarette for the first time. & 45.5 \\
$<14$ & 1 & 24.2 \\
$15-16$ years & 9 & \\
$>16$ & 15 & \\
Haven't smoke an entire cigarette & & \\
& &
\end{tabular}




\begin{tabular}{lll}
\hline Total & 33 & 100.0
\end{tabular}

Twenty four percent $(24.2 \%)$ hadn't smoked an entire cigarette, because they wanted just to try how smoking felt like and some didn't like the feeling at the first attempt.

When considering the places of smoking, majority (45.5\%) had smoked in social events, followed by $27.3 \%$ who had smoked in a friends' house and $24.2 \%$ had smoked in their own house. There were $15.2 \%$ who smoked in public places.

Although all the participants were under 21 years of age, majority (48.5\%) of them had bought cigarettes by their own. Twenty one percent (21.2\%) of them had given money to someone else to buy cigarettes for them and $27.3 \%$ of them had got cigarettes in other ways such as from relatives and friends.

\section{Attitudes towards smoking among students who had ever smoked}

Reasons that made students smoke frequently and not to smoke frequently, feelings after smoking, religious and ethnic group believes on smoking were considered as attitudes.

Students who had smoked more than 6 cigarettes were considered as frequent smokers. Among 33 male students who had ever smoked, 16 had smoked more than six cigarettes. Following reasons were considered and participants were asked to mark more than one response (Table 2).

Table 2: Reasons for frequent smoking among students in the study sample

\begin{tabular}{lcc}
\hline \multicolumn{1}{c}{ Reasons for smoke frequently } & No. of students & percentage (\%) \\
\hline Been around smokers a lot of time & 11 & $68.75 \%$ \\
Had found smoking pleasurable & 10 & $62.50 \%$ \\
Smoking had helped feel less stressed & 10 & $62.50 \%$ \\
Had enjoyed the taste & 1 & $6.25 \%$ \\
Smoking had helped focus and concentrate better & 1 & $6.25 \%$ \\
Had smoked to fit in with other people & 6 & $37.50 \%$ \\
Had liked the image of a smoker & 1 & $6.25 \%$ \\
Family members had smoked & 2 & $12.50 \%$ \\
Other & 8 & $50.00 \%$
\end{tabular}

Among those who had smoked less than 6 cigarettes, 94\% had not smoked frequently because they had concerned about the effects of smoking on own health, $35.3 \%$ of boys did so because they had not liked the taste and the smell of cigarettes, had concerned about the effects of smoking on others health, had grown up in a non-smoking family, $11.8 \%$ had do so because smoking had made them feel sick and/or they had stopped hanging out with smokers, had been encouraged to stop smoking by their parents and teachers and/or could not afford cigarettes.

When considering the religious influence on smoking, both the majority who had ever smoked (78.8\%) and who had never smoked (89.2\%) had the same idea that their religious community had not approved smoking. And regarding the ethnic group influence also majority who had ever smoked (63.6\%) and who had never smoked (58.1\%) both had the same idea that their ethnic group had not approved smoking.

\section{Factors associated with smoking}

Individual factors, family background, social influence and current regulations implemented in the country regarding smoking were considered as associated factors with smoking. Chi- square test was applied to see if 
there is a statistically significant association between each factor with the outcome, except for the factors that were considered under 'current regulations implemented in the country, smoking status was taken as the outcome.

Individual factors: Life satisfaction, the degree of stress experience in their lives and study performance were considered as individual factors. Above factors have no statistically significant association with smoking among the study group $(\mathrm{p}>0.05)$.

Family background: Monthly family income (rupees), the amount of own expenses (rupees) receiving per month, status of parental/ guardian smoking and siblings smoking, acceptance of visitors to smoke inside home, acceptance of smoking inside own home by parents and advice from parents regarding dangers of smoking were considered under family background. Among those presence of parental/ guardian smoking $(\mathrm{p}=0.013)$, siblings smoking $(\mathrm{p}=0.001)$, acceptance of visitors to smoke inside home $(0.001)$, showed a statistically significant association with smoking among the students in the study group $(\mathrm{p}<0.05)$.

Social influence: Presence of closer friends' who smoke $(\mathrm{p}=0.001)$, pleasurable thoughts of peers regarding smoking $(p=0.004)$, knowledge from school regarding dangers of smoking $(p=0.007)$ and seen/heard of antismoking advertisements on social media $(\mathrm{p}=0.02)$ showed a statistically significant association with smoking among the students in the study group $(\mathrm{p}<0.05)$.

Influence of current regulations implemented in the country regarding smoking: Influence of pictorial health warning on cigarette packets and the law of "minimum age to purchase tobacco products" were considered. Majority (35.5\%) of the boys who had ever smoked hadn't bought a pack, followed by $30.3 \%$ who had no effect of pictorial health warning on cigarette packs towards their smoking and only $9.7 \%$ were influenced to quit smoking. Majority (59.5\%) had seen a seller refusing to sell the cigarettes sometimes because of the inadequate age followed by $20 \%$ who had never seen that.

\section{Discussion}

In the current study, the overall prevalence of ever smoking was $16 \%$. There were several studies carried out among school children on smoking between the ages of 11 to 18 years in Sri Lanka. The prevalence of smoking had ranged from $10 \%$ to $17 \%$ among males and $0.1 \%$ to $0.3 \%$ among females (Mendis et al, 1990). The prevalence of male smoking has reduced over time in subsequent studies (Gunasekara, 2003). Another previous study conducted among adult males in Colombo district reported that the prevalence of ever smoking as $54.1 \%$ (95\%CI 51-57.2) (Chulasiri, 2014). In 2015, a school based survey conducted in Colombo district reported that prevalence rate for males as $27 \%$ (Katulanda et al, 2015). However this variation of smoking prevalence among adolescents in these studies might be due to the differences in sampling, sample size, smoking definition and social circumstances. The sample recruited in our study is of lower age (17-18) category when compared with previous studies. In addition, limiting this study to the Advanced level biology tuition class in Gampaha district might also contributed to the reporting of a slightly lower prevalence of smoking.

Studies in developed countries have revealed that majority of the people who smoked started the habit before the age of 18 years. Initial exposure at younger age is a documented risk factor for heavier tobacco use as an adult (Fernandez et al, 1999). In the present study we observed that majority of them had the initial exposure to cigarette smoking at the age between 15 to 16 years of age. Many factors including home environment, income status, parental smoking and peer pressure have been reported to be associated with smoking among children and adolescents in other countries (Leventhal et al, 1980). A higher prevalence of smoking among younger age categories has been observed in India. Effects of these factors may be different in Asian countries like Sri Lanka where children are brought up in a different cultural background which reinforced a possible role of parental monitoring in preventing adolescent smoking. 
Large number of previous studies had reported the effect of personal characteristics in adolescents' smoking initiation and continuation. The family influence has been extensively analyzed and a wide range of family factors were reported to be associated with adolescent smoking. Current study also provide consistent evidence on the influence of parental smoking with their children's current smoking behavior. This study also reported that other family factors such as siblings' smoking, permission of visitors to smoke inside the home, strongly associated with their child's smoking. We observed that having a close friend who smoked were the most significant factor for smoking.

The previous studies had shown that students in the Advanced Level classes who were studying in arts and commerce streams (non-science subjects) had 3.03 and 2.5 times the odds to have smoked in their life time when compared with a student following the biological sciences stream $(\mathrm{OR}=1.54, \mathrm{p}<0.001)$ (Katulanda et al, 2015). This may also contributed to the relative low prevalence of smoking among our study sample.

Current study showed that anti-smoking advertisement on social media positively associated with non-smoking status. This implies the effectiveness of current prohibition of tobacco advertising, promotions and sponsorship which are acting as cigarette vending machines.

\section{Limitations}

Since it was a cross sectional design, it could not provide causal associations. The smoking status of the participants was collected via a self-administered questionnaires, this might underestimate the smoking prevalence among adolescents. The present study was confined to advanced level biology tuition class considering the feasibility, available time frame and resources. So the findings may not be generalizable to the whole advanced level student population in Sri Lanka.

\section{Conclusions and recommendations}

In conclusion, the prevalence of smoking was relatively high among advanced level biology students in Gampaha district in Sri Lanka. The personal characteristics played an important role in initiation and continuation of adolescents' smoking. Parental smoking, siblings smoking and close friends smoking remained to be significant associated factors. There for students should be equipped to resist social influences that encourage smoking. The knowledge of health consequences of smoking such as lung and laryngeal cancers and anti-smoking advertisement on social media acts as refraining factor from smoking. Hence, we should give more emphasis towards these factors when we plan anti-smoking programs and policies and regulations regarding smoking. Current rules and regulations on smoking should be further strengthen in order to have a positive impact. Retail selling of cigarettes should be prohibited in order to get the maximum impact of pictorial health warning. However further researches will be needed for complete understanding of this issue.

\section{Acknowledgement}

We would like to acknowledge the Department of Community Medicine, Faculty of Medicine, University of Colombo for giving the opportunity to conduct this research.

\section{References}

Bartecchi, C.E., MacKenzie, T.D. and Schrier, R.W., 1994. The human costs of tobacco use. New England Journal of Medicine, 330(13), pp.907-912.

'Brief profile on Tobacco Control in Sri Lanka (2009) www.adicsSriLanka.org

Camenga, D.R., Klein, J.D. and Roy, J., 2006. The changing risk profile of the American adolescent smoker: implications for prevention programs and tobacco interventions. Journal of Adolescent Health, 39(1), pp.120-e1. 
Choi, S.H. and Kim, Y.H., 2016. Factors affecting Korean registered nurses' intention to implement smoking cessation intervention. Osong public health and research perspectives, 7(1), pp.63-70.

Chulasiri, M., 2014. Prevalence and associated factors of smoking among adult males in Colombo district and cost of treatment of lung cancer attributed to smoking (Doctoral dissertation, Doctoral Thesis. Sri Lanka: Post Graduate Institute of Medicine, University of Colombo).

Fernandez, E., Schiaffino, A., La Vecchia, C., Borràs, J.M., Nebot, M., Saltó, E., Tresserras, R., Rajmil, L., Villalbj, J.R. and Segura, A., 1999. Age at starting smoking and number of cigarettes smoked in Catalonia, Spain. Preventive Medicine, 28(4), pp.361-366.

Kandel, D.B., Kiros, G.E., Schaffran, C. and Hu, M.C., 2004. Racial/ethnic differences in cigarette smoking initiation and progression to daily smoking: a multilevel analysis. American Journal of Public Health, 94(1), pp.128-135.

Katulanda, P., Liyanage, I.K., Wickramasinghe, K., Piyadigama, I., Karunathilake, I.M., Palmer, P.H. and Matthews, D.R., 2015. Tobacco smoking among school children in Colombo District, Sri Lanka. Asia Pacific Journal of Public Health, 27(2), pp.NP278-NP287.

Khuder, S.A., Dayal, H.H. and Mutgi, A.B., 1999. Age at smoking onset and its effect on smoking cessation. Addictive behaviors, 24(5), pp.673-677.

Leventhal, H. and Cleary, P.D., 1980. The smoking problem: a review of the research and theory in behavioral risk modification. Psychological bulletin, 88(2), p.370.

Lydon, D.M., Wilson, S.J., Child, A. and Geier, C.F., 2014. Adolescent brain maturation and smoking: what we know and where we're headed. Neuroscience \& Biobehavioral Reviews, 45, pp.323-342.

Mendis, S., 1990. Tobacco use in a cohort of children in Sri Lanka. British journal of addiction, 85(3), pp.397398.

Noar, S.M., Hall, M.G., Francis, D.B., Ribisl, K.M., Pepper, J.K. and Brewer, N.T., 2016. Pictorial cigarette pack warnings: a meta-analysis of experimental studies. Tobacco control, 25(3), pp.341-354.

Pavanello, S. and Clonfero, E., 2000. Biomarkers of gentotoxic risk and metabolic polymorphism. La Medicina del lavoro, 91(5), pp.431-469.

Sieminska, A., Buczkowski, K., Jassem, E., Lewandowska, K., Ucinska, R. and Chelminska, M., 2008. Patterns of motivations and ways of quitting smoking among Polish smokers: a questionnaire study. BMC Public Health, 8(1), p.274.

Singh, G., Sinha, D.N., Sarma, P.S. and Thankappan, K.R., 2005. Prevalence and correlates of tobacco use among 10-12 year old school students in Patna district, Bihar, India. Indian pediatrics, 42(8), p.805.

Twyman, L., Bonevski, B., Paul, C. and Bryant, J., 2014. Perceived barriers to smoking cessation in selected vulnerable groups: a systematic review of the qualitative and quantitative literature. BMJ open, 4(12), p.e006414.

World Health Organization (2007); Tobacco or health: a global status report. http://www.who.int/tobacco/publications/tobacco_report_2007/en. 